Mediterránea, 5 - Págs. (35 - 41), Año 1981

\title{
SOBRE LA INFLUENCIA ATLÁNTICA EN LA FLORA DE LA SIERRA DE MIRA (CUENCA, ESPAÑA)
}

\author{
Por Gonzalo Mateo \\ Departamento de Botánica. \\ Fac. Ciencias Biológicas. \\ Universidad de Valencia.
}

La Sierra de Mira es un sistema montañoso que comienza en las elevaciones situadas entre Camporrobles y Mira, en el límite de las provincias de Valencia y Cuenca; sigue en dirección al NE. a través de una línea de crestas con altitudes entre 1.200 y $14.40 \mathrm{~m}$., y acaba en el valle del Turia, entre los términos de Tuéjar y Aras de Alpuente.

En ella se aprecia una gran riqueza y variabilidad en cuanto a flora y vegetación, gracias a reunirse alli varios factores entre los que destacan:

- Una situación geográfica puente entre dos regiones naturales, tan peculiares y diferenciadas, como son la meseta ibérica y el litoral levantino. Lo cual se concreta corológicamente en ser la frontera entre las provincias Castellano-Maestrazgo-Manchega y Valenciano-Catalano-Provenzal-Balear. (Rivas-Martínez, 1973).

- Una gran variabilidad de sustratos geológicos, desde cuarcitas paleozoicas hasta llanuras cuaternarias de aluvión pasando por importantes masas de areniscas y conglomerados triásicos, calizas jurásicas y cretácicas y diversas rocas sedimentarias terciarias.

Dentro de la variada gama de condiciones ecológicas asi originadas algunas de ellas tienden a favorecer el desarrollo de las especies y comunidades de óptimo atlántico o subatlántico; principalmente las siguientes:

$1^{\circ}$.- La presencia de montañas de elevación relativamente im- 
portante (Pelado 1.422 m., Mazmorra 1.411, Ranera 1.430), a una distancia de $90-95 \mathrm{kms}$. del mar, sin que se presente ninguna otra sierra más elevada de por medio.

$2^{\circ}$.- La gran superficie cubierta por sustrato silícico, principalmente areniscas y conglomerados triásicos, así como cuarcitas ordovícicas y sedimentos arenosos cuaternarios producto de la disgregación de las anteriores rocas. Todos ellos originadores de suelos con mucha mayor capacidad de retención de agua que los calizos.

$3^{\circ}$.- Las precipitaciones recibidas, bastante más elevadas que las de los llanos periféricos a la sierra, pues superan los $600 \mathrm{~mm}$. en las áreas de mediana elevación, y alcanzan los $700-800 \mathrm{~mm}$. en las más elevadas; siendo siempre la sequía estival no demasiado acusada; por lo que podemos calificar su bioclima de subhúmedo. (Rivas-Martínez, 1979).

Dentro de las múltiples especies concretas, de carácter en alguna medida atlántico, que se presentan, vamos a elegir y comentar algunas de las más representativas; aclarando que tomamos el concepto de atlánticas en su sentido más amplio, y sin matizar subdivisiones del elemento, por otro lado sujetas a constante revisión a medida que avanzan los conocimientos sobre las áreas de las especies y, por tanto, muy discutibles y no aceptadas de un modo unificado por los especialistas.

Podemos, sin embargo, afirmar que están ausentes los elementos euatlánticos, en sentido restringido (Dupont, 1962) exclusivos de la provincia Atlántica; por lo que los táxones que alcanzan esta zona son elementos subatlánticos, atlántico-mediterráneos, subatlántico-submediterráneos, etc.

Quercus pyrenaica Willd. : Genuíno representante de la flora iberoatlántica, con óptimo en las montañas mediterráneas sometidas a mayor influencia atlántica. Resulta relativamente abundante en esta sierra, en localidades protegidas de las montañas silicicas; a donde llega, como puede apreciarse en el mapa (fig. $1 .^{a}$ ) por via ibérica, alcanzando allí uno de sus límites en cuanto a penetración en territorio mediterráneo.

Cytisus scoparius (L.) Link. : Más extendido que el anterior por la provincia atlántica, resulta igualmente abundante por el territorio iberoatlántico, presentando un areal similar en la península ibérica, y alcanzando de modo finicola los rodenos de la sierra de Mira.

Viola riviniana Reichenb. : De área más amplia en Europa, se comporta en la península como iberoatlántica. Presente en las umbrias más frescas de nuestra sierra, en el área potencial del melojar.

Carum verticillatum (L.) Koch : Especie de acentuado matiz 


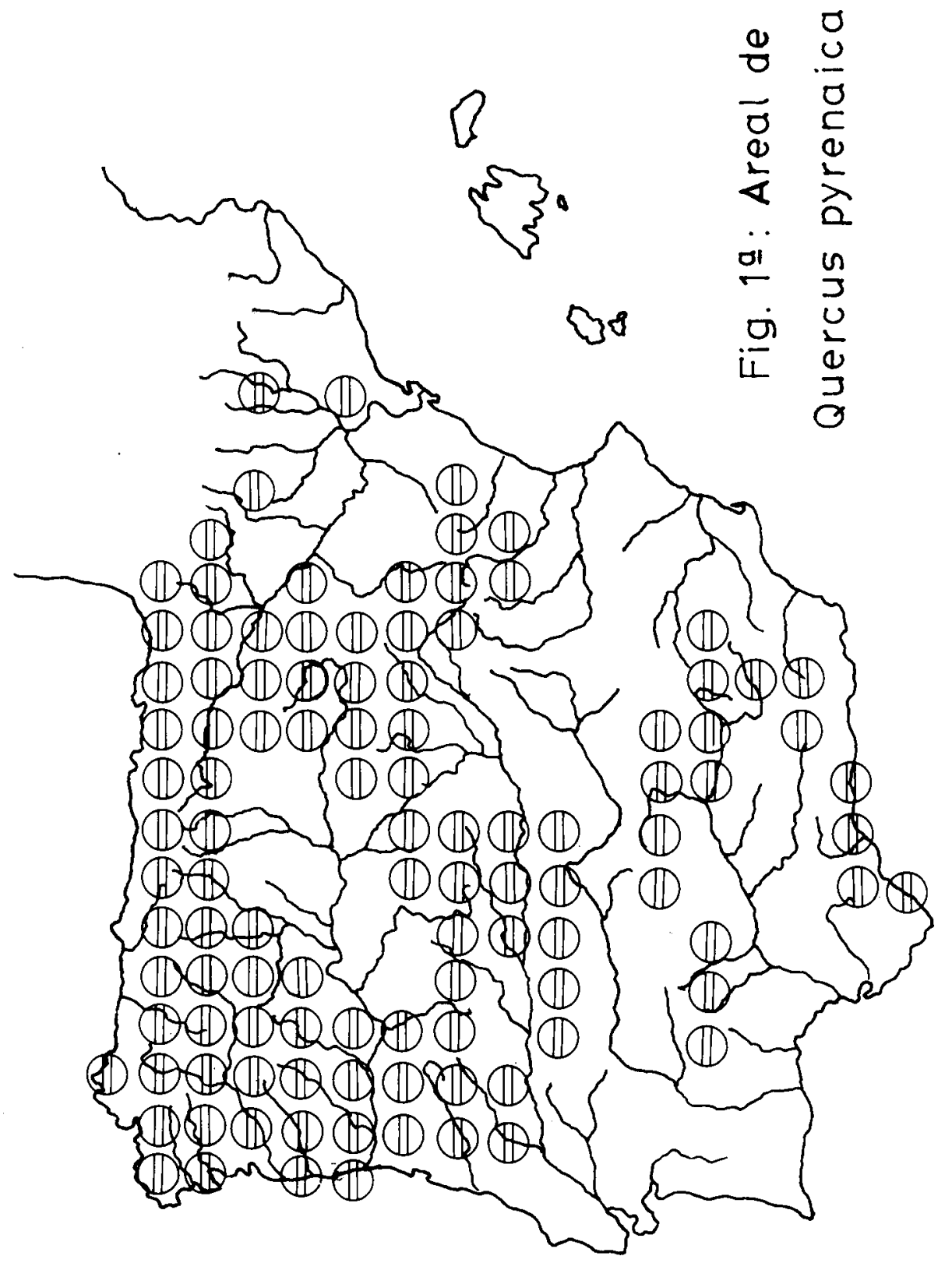


atlántico, relativamente frecuente en esta zona, donde se refugia en los juncales de MOLINIETALIA y HOLOSCHOENETALIA sobre suelos más húmedos.

Erica cinerea L.: Quizá la especie más claramente atlántica de las encontradas en la zona. Común en los brezales de la gran provincia atlántica, desde Portugal a las costas del mar del Norte; penetra en el Pirineo occidental (Villar, 1980), en algunas áreas mediterráneas del sur de Francia (Aubert, Barbero \& Loisel, 1971), en Cataluña (Font Quer 1949, O. de Bolós 1951) y el macizo Ibérico. Dentro de éste resulta abundante en las sierras de la Demanda y Urbión (Vicioso, 1941), con mayor influencia atlántica; de donde pasa a la rama nororiental del Sistema Central (S. ${ }^{a}$ de Ayllón, Mayor 1964) y a la Serrania de Cuenca (G. López, 1976), alcanzando su limite en el territorio que estamos considerando (Fig. 2. ${ }^{a}$ ).

Calluna vulgaris (L.) Salisb.: Como la anterior, tiene su óptimo en los brezales atlánticos, aunque su área es amplia y mayor su penetración en territorio mediterráneo. Muy abundante en esta sierra, donde interviene en gran número de comunidades silicícolas de brezal, jaral, pinar, etc.

Anagallis tenella L.: Especie ya conocida de áreas iberolevantinas, en concreto del valle del Júcar (Rivas Goday \& Mansanet, 1972), donde se asocia con Erica erigena $R$. Ross sobre suelos permanentemente húmedos. En la sierra de Mira aparece en márgenes de arroyos de montaña, en comunidades de MOLINIOHOLOSCHOENION en transición hacia las de MONTIO CARDAMINETEA.

Littorella uniflora (L.) Asch.: Casi desconocida en las áreas mediterráneas peninsulares. Se presenta en esta zona en una laguna próxima a Sinarcas, en comunidades fragmentarias de LITTORELLETEA, pertenecientes a la alianza Eleocharition multicaulis.

Campanula lusitanica L.: Especie de óptimo iberoatlántico, común en los pastizales terofíticos silicícolas de la mitad oeste de la península, que encuentran en estas montañas su limite oriental.

Jasione crispa (Pourret) Sampaio subsp. sessiliflora (Boiss. \& Reuter) Rivas-Martínez: Especie propia de la subprovincia cántabroatlántica, que penetra discretamente en territorio mediterráneo, a través de algunas de sus subespecies, como la presente.

Narcissus pseudonarcissus L.: Especie de importantes requerimientos hídricos, con óptimo en áreas atlánticas, escasamente representada en área mediterránea; siendo ésta, pese a presentarse abundantemente en ella, una de sus localidades extremas.

Danthonia decumbens (L.) DC.: Frecuente en los pastizales húmedos atlánticos y medioeuropeos, alcanza en esta zona uno de sus límites en cuanto a penetración en territorio mediterráneo. 


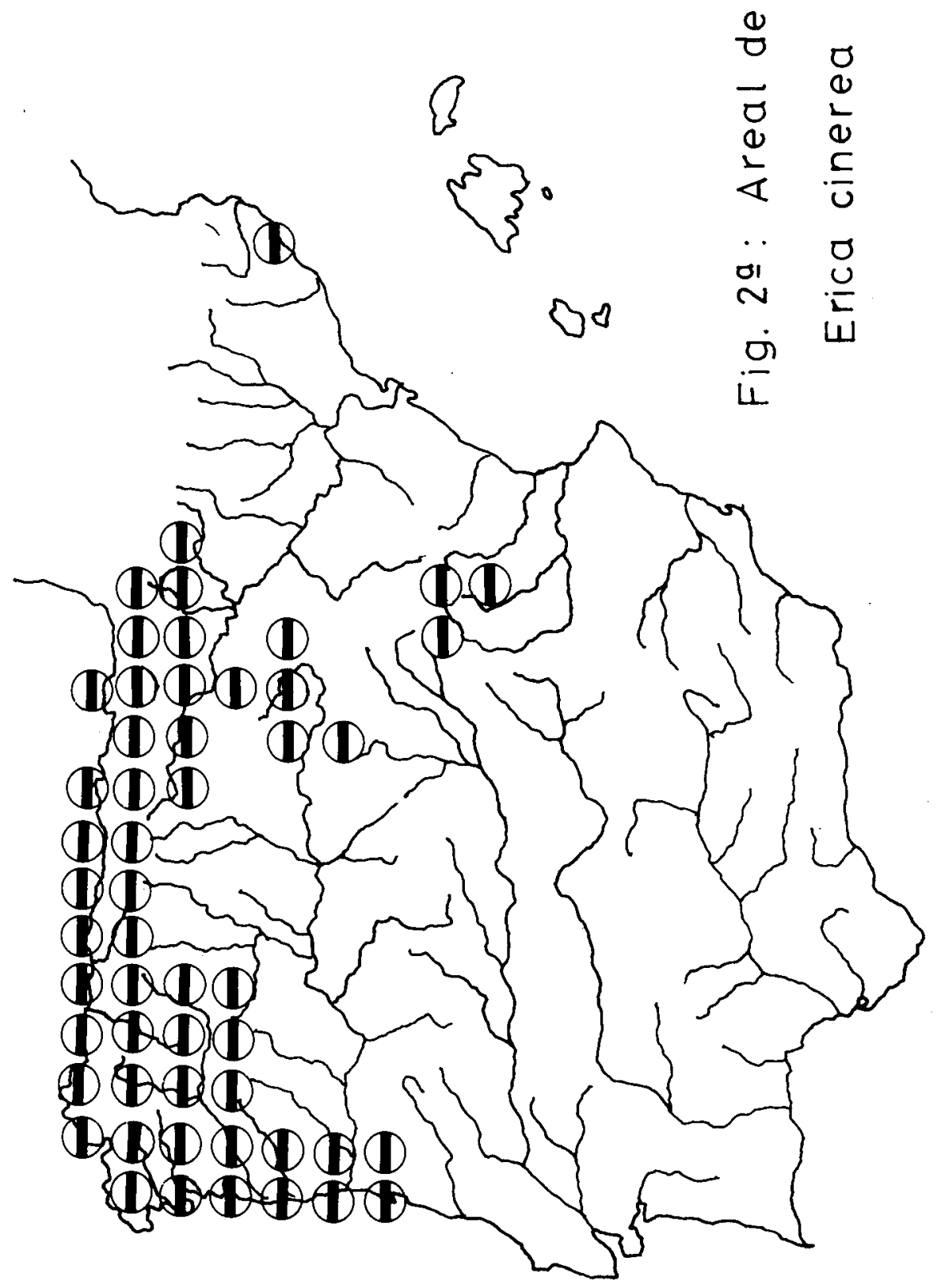


Anthoxanthum amarum Brot.: Interesante especie, considerada en el reciente último tomo de Flora Europea como endémica del NW ibérico, pero que llega a alcanzar la provincia de Valencia por las umbrías de las montañas silícicas de la sierra de Mira; presentándose en los herbazales densos de los claros de bosque.

Eleocharis acicularis (L.) Roemer \& Schultes y E. multicaulis (Sm.) Desv.: Estas dos pequeñas ciperáceas de óptimo atlántico, casi desconocidas en área mediterránea ibérica, se presentan bastante localizadas, sobre suelos inundados casi todo el año, en comunidades de Eleocharition multicaulis. 


\section{BIBLIOGRAFIA COMENTADA EN EL TEXTO.}

AUBERT, G.; M. BARBERO \& R. LOISEL (1971). Les callunaies dans le sud-est de la France et le nord-ouest de l'Italie. Bull. Soc. Bot. Fr. 118: 679-700.

BOLOS, $O$. de (1951). El elemento fitogeográfico eurosiberiano en las sierras litorales catalanas. Collec. Bot. III: 1-41.

DUPONT, P. (1962). La Flore atlantique européenne. Introduction à l'étude du secteur Ibero-Atlantique. Doc. Cart. Pr. Veg., Fac. Sciences, Toulouse.

FONT QUER, P. (1949). Acerca de la presencia de algunas plantas atlánticas y subatlánticas en Cataluña. Portugalia Acta Biol. ser. B: 87-96.

LOPEZ, G. (1976). Contribución al conocimiento fitosociológico de la Serranía de Cuenca. I. Anal. Inst. Bot. Cav. 33: 5-87.

MAYOR, M. (1964). Especies pirenaicas en el tramo oriental del Sistema Central. Anal. Inst. Bot. Cav. 22: 409-420.

RIVAS GODAY, S. \& J. MANSANET (1972). Acerca del comportamiento edáfico de la Erica mediterranea (hibernica) en España. Anal. R. Acad. Farm. 38: 95-106.

RIVAS-MARTINEZ, S. (1973). Avance sobre una sintesis corológica de la Peninsula Ibérica, Baleares y Canarias. Anal. Inst. Bot. Cav. 30: 69-87.

- -(1979). Brezales y jarales de Europa occidental (Revisión fitosociológica de las clases Calluno-Úlicetea y Cisto-Lavanduletea). Lazaroa 1: 5-127.

VICIOSO, C. (1941). Materiales para el estudio de la flora soriana. Anal. Jard. Bot. Madrid 2: 188-236.

VILLAR, L. (1980). Catálogo floristico del Pirineo occidental español. P. Cent. Pir. Biol. Exp. n. ${ }^{\circ} 11$, Jaca.

\section{RESUMEN}

A consecuencia de reunirse una serie de factores climáticos, topográficos y geológicos particulares, se presentan en la sierra de Mira, limitrofe entre las provincias de Cuenca y Valencia, una serie de especies vegetales son marcada influencia atlántica, cuyas peculiaridades se comentan brevemente. 